

\section{INDICE}

EDITORIAL PERSONAL ÁMBITOS

Apresentação do monográfico. Abordagem qualitativa: olhares e práticas transdisciplinares nas ciências antropossociais

Presentation of the monograph. Qualitative approach: transdisciplinary views and practices in anthroposocial sciences

Ronaldo Nunes Linhares, António Pedro Costa

MONOGRAFICOS MONOGRAPHS

Identidades femininas na rede: as crianças falam!

Female identities on line: children can speak

Marta Maria Azevedo Queiroz

$12-31$

Transição de cuidados de enfermagem: ISBAR na promoção da segurança dos

doentes - revisão scoping

Transition of nursing care: ISBAR in promoting patient safety - scoping review

Ana Rita Esteves Figueiredo, Teresa Maria Ferreira dos Santos Potra, Pedro Ricardo Martins Bernardes Lucas

$32-48$

Integración de elementos cualitativos y cuantitativos en metodología observacional

Integration of qualitative and quantitative elements in observational methodology

M. Teresa Anguera, Angel Blanco-Villaseñor, José Luis Losada, Pedro Sánchez-Algarra

49-70

Atos educativos com oficines de ecografias: uma investigação otobiográfica

Educational acts at echographie's cineliers: an otobiographic research

Silas Borges Monteiro, Anaise Avila Severo

Actuación de las políticas: política como texto y política como discurso

Action of policies: policy as text and policy as discourse

Mónica Rocío Barón

88-104 


\section{ÁMBITOS PERSONALES PERSONAL ÁMBITOS}

Un retrato de la cultura local a través del Periodismo cultural. Análisis comparado de Sevilla y Porto Alegre

A portrait of the local culture through cultural Journalism. Comparative analysis of Seville and Porto Alegre

\section{ARTÍCULOS ARTICLES}

Microsociología del profesor universitario

Microsociology of an university professor

Antonio Fernández Vicente

La pobreza y el discurso de los mass media. Un estudio de la prensa local argentina

Poverty and mass media 's discourse. A study of the Argentine local press

María del Rosario Sanchez, Silvia London

La comunicación no verbal en las elecciones andaluzas de 2018. Comparativa de Susana Díaz y Teresa Rodríguez en el debate de RTVE

Non-verbal communication in the Andalusian municipal elections of 2018. Comparison of Susana Díaz and Teresa Rodríguez in the electoral RTVE debate

María Hernández Herrarte, Patricia Zamora-Martínez

El infoentretenimiento en la televisión de pago, Movistar+ y el canal \#0.

El uso transmedia de sus contenidos de humor

Infotainment on pay television, Movistar+ and channel \# 0 . The transmedia use of its humorous content

Metodología y formación docente cuestiones claves para la integración de las TIC en la educación

Methodology and teacher training as a key issue for ICTs integration in Education 


\section{RESEÑAS REVIEWS}

Aquelarre. Mujeres en la cultura de masas

Coven. Women in mass culture

Regla Ismaray Cabreja Piedra

216-220

Transición ecosocial y principios éticos en el periodismo: una guía para la comunicación de nuevas narrativas

The Eco-social transition and ethical principles in journalism: a guide for the communication of new narratives

Amanda Salazar Torres

Narrativas ecofeministas y mapa de transición ecosocial para medios de comunicación Eco-feminist narratives and ecosocial transition map for the media 


\title{
La comunicación no verbal en las elecciones andaluzas de 2018. Comparativa de Susana Díaz y Teresa Rodríguez en el debate de RTVE
}

\author{
Non-verbal communication in the Andalusian municipal \\ elections of 2018. Comparison of Susana Díaz and Teresa \\ Rodríguez in the electoral RTVE debate
}

\author{
María Hernández Herrarte, España, Universidad Europea Miguel de Cervantes, \\ Padre Julio Chevalier, 2, 47012, Valladolid, España \\ mhernandez@uemc.es | Orcid: https://orcid.org/0000-0002-4399-2260 \\ Patricia Zamora-Martínez, España, Universidad de Valladolid, Plaza del Campus \\ Universitario, s/n, 47011, Valladolid, España \\ patricia.zamora@uva.es | Orcid: https://orcid.org/0000-0002-5730-7295
}

DOI: https://dx.doi.org/10.12795/Ambitos.2020.i49.10

\begin{abstract}
Resumen
Dada la gran repercusión que tiene la imagen televisiva sobre los espectadores, la comunicación no verbal (CNV) ha adquirido un papel clave en el actual terreno político. En este sentido, los debates electorales se convierten en eventos de gran repercusión debido a la posibilidad que brindan de observar y juzgar a los candidatos. Por este motivo, el esfuerzo de los asesores políticos se centra en aportar sentido al discurso oral mediante el uso correcto de los códigos no verbales. El principal objetivo del artículo es aumentar los estudios sobre CNV en la política española y, particularmente,
\end{abstract}


incrementar los realizados a políticas en el contexto de los debates electorales, con el fin de comprobar si las claves persuasivas utilizadas en estos encuentros son similares o difieren entre géneros. En concreto, se ha comparado el comportamiento kinésico de dos candidatas a la Junta de Andalucía por el Partido Socialista Obrero Español y Adelante Andalucía, Susana Díaz y Teresa Rodríguez, líderes femeninas enfrentadas tanto en su ideario como en su oratoria, durante el debate electoral retransmitido en RTVE por el canal 24 horas el 26 de noviembre de 2018. La metodología se basa en el análisis de contenido cuantitativo, una técnica que mide con rigor y fiabilidad la frecuencia de patrones gestuales utilizados. Los resultados permiten establecer una radiografía de variables gestuales de ambas candidatas que apunta a que fue Susana Díaz quien desplegó una CNV más positiva en términos de persuasión durante el tiempo que intervino frente a su oponente.

\begin{abstract}
Given the great repercussion that the television image has on viewers, non-verbal communication (CNV) has acquired a key role in the current political terrain. In this sense, electoral debates become events of great repercussion due to the possibility that they offer to observe and judge the candidates. For this reason, the effort of political advisers is focused on making sense of oral discourse through the correct use of nonverbal codes. The main objective of the article is to increase studies on CNV in Spanish politics and, particularly, to increase studies on politics in the context of electoral debates, in order to check whether the persuasive keys used in these meetings are similar or differ between genders. Specifically, the kinesic behavior of two candidates for the Junta de Andalucía by the Partido Socialista Obrero Español and Adelante Andalucía, Susana Díaz and Teresa Rodríguez, female leaders faced both in their ideology and in their oratory, was compared during the broadcast electoral debate in RTVE on the 24 hours channel on November 26, 2018. The methodology is based on quantitative content analysis, a technique that rigorous and reliably measures the frequency of gestural patterns used. The results allow establishing an $X$-ray of the gestural variables of both candidates, which indicates that it was Susana Díaz who deployed a more positive CNV in terms of persuasion during the time she intervened in front of her opponent.
\end{abstract}

Palabras clave: Comunicación no verbal, debate electoral, líderes políticas femeninas, persuasión, elecciones andaluzas

Keywords: Non-verbal communication, electoral debate, women political leaders, persuasion, Andalusian elections

\title{
1. INTRODUCCIÓN
}

El estudio de las categorías que conforman la comunicación no verbal, especialmente la kinesia, en el terreno de la comunicación política ha estado ligado, en la mayoría de 
las investigaciones nacionales, a las distintas citas electorales. Concretamente, el estudio de los distintos códigos no verbales se limita, casi en exclusividad, a las actuaciones de los políticos durante los debates electorales.

Metodológicamente, el trabajo realizado por Hernández y Rodríguez (2009) supone un referente en esta cuestión. Estas autoras proponen una metodología de análisis de comportamiento no verbal para el estudio de representantes políticos expuestos ante los medios de comunicación.

En cuanto al estudio de las categorías no verbales, nuevamente, las autoras Rodríguez y Hernández (2009) y la autora Hernández (2012) profundizan en el comportamiento kinésico de varios políticos y candidatos. Las primeras, realizan un análisis del comportamiento kinésico de los expresidentes españoles Zapatero y Rajoy en los debates de 2008 y la segunda, aborda el comportamiento kinésico de José Luis Rodríguez Zapatero durante el curso político 2006-2007 comparándolo con la temática de su discurso. Enmarcado en este análisis, también se encuentran los trabajos de Orzáiz (2009) con su estudio sobre la comunicación no verbal y paraverbal en el debate político entre Zapatero y Rajoy; la de Rodríguez Escanciano y Hernández (2011) en la que se realiza un estudio pormenorizado del lenguaje no verbal del expresidente del Gobierno español, José Luis Rodríguez Zapatero, en el primer trimestre del año 2010 , y la realizada por Lasheras (2014) centrada en el análisis de la dimensión no verbal de Alfredo Pérez Rubalcaba y Mariano Rajoy en los debates electorales de 2008. Más reciente es el trabajo de Pérez y Lancharro (2017) sobre las estrategias de comunicación verbal y no verbal de Podemos y Ciudadanos en los debates electorales.

Las investigaciones de Torregrosa (1999), López y Méndez (2009) y Espizua y Padilla (2017) analizan otras categorías no verbales, como la correlación de los patrones entonativos y kinésicos durante el debate televisado en el primer caso, el paralenguaje de Zapatero y Rajoy en el segundo, o el aspecto físico y la apariencia de la mujer política española en el tercero.

El objetivo general de esta investigación es incrementar los estudios sobre la comunicación no verbal en la política española y, de manera particular, aumentar los que centran su estudio en la comunicación no verbal de candidatas políticas en el contexto de los debates electorales.

El artículo tiene la siguiente estructura: inicialmente se presenta una introducción sobre la literatura existente en torno a la comunicación política y la comunicación no verbal. A continuación, se detalla la importancia de los debates electorales y la comunicación no verbal de los políticos en los mismos, profundizando en cuáles son las categorías que se asocian con una comunicación positiva o negativa en términos persuasivos. Después de la base teórica, se explica la metodología utilizada para, finalmente, presentar los resultados, la discusión y las conclusiones. 


\section{MARCO TEÓRICO}

En España no existe una larga tradición en la celebración de debates electorales, debido casi con toda seguridad a que, como afirma García Marín (2015), "los grandes partidos políticos no han visto en ellos beneficios reales para sus campañas electorales” (p.137).

El primero se celebró el 24 de mayo de 1993. Por primera vez en la historia contemporánea del país, los ciudadanos pudieron seguir las retransmisiones de los debates a la presidencia del Gobierno entre Felipe González (PSOE) y José María Aznar (PP). Desde entonces, se han organizado nueve debates electorales con la presencia de los principales candidatos a la presidencia del Gobierno en las catorce elecciones generales que se han organizado. El último se pudo ver el 4 de noviembre de 2019 y reunió, por primera vez en la historia del país, a cinco líderes con representación parlamentaria: Pablo Casado (PP), Pedro Sánchez (PSOE), Pablo Iglesias (Unidos Podemos), Albert Rivera (Ciudadanos) y Santiago Abascal (Vox). La organización de este debate se produjo ocho meses después del anterior de abril de 20191, ante la falta de acuerdos para aprobar los presupuestos generales para 2019.

Los estudios sobre los debates electorales han estado desde siempre monopolizados por Estados Unidos (Luengo, 2011) debido a que su tradición por la realización de estos viene de muy atrás, especialmente en el caso de los televisados. En España, el reciente interés por este formato se incrementó a raíz de los celebrados para los comicios de 2008 (García-Marín, Calatrava y Luengo, 2018), en los que se enfrentaron Mariano Rajoy (PP) y José Luis Rodríguez Zapatero (PSOE). Desde entonces, los debates han suscitado un interés elevado entre los telespectadores de nuestro país, como muestran los últimos datos de audiencia sobre el último emitido el 4 de noviembre 20192 que registró 7.755 .000 de espectadores y una cuota de pantalla del 47,4\%, según Barlovento Comunicación (2019). De ahí que la televisión se haya convertido en el medio preferido de los candidatos, pues conocen la fuerza que tiene sobre la sociedad, como expone la autora Berrocal (2001): "Este fenómeno [la televisión] produce una serie de efectos sobre algunas personas, futuros votantes, en determinados sentidos, en determinadas condiciones (...) y en determinados aspectos: cognitivo (conocimiento, información), afectivo (sentimientos, evaluación, interés) y forma de actuar (votando)" (p.148).

En el plano de la comunicación no verbal, algunos debates históricos internacionales y nacionales demuestran cómo "en televisión tienen tanta o más importancia las formas con que se presentan los mensajes, que los mensajes mismos" (Barnés, 2007, p.93). El celebrado en Estados Unidos entre Richard Nixon y John Fitzgerald Kennedy en $1960_{3}$ evidenció la importancia de la imagen en estos eventos. Nixon buscó transmitir su experiencia presidencial olvidándose de su imagen, mientras Kennedy conquistó muchos votos por su actuación técnica, profesional y por el cuidado que prestó a su imagen, lo que le permitió ganar. Según Gubern (2008), la explicación del éxito del 
segundo se encuentra en el predominio que adquirió el lenguaje visual sobre el discurso verbal.

El look y el glamour, cualidades sensitivas desbancaron a la dimensión reflexiva [de Nixon] que es una cualidad intelectual... el factor personal de los candidatos, su voz, su elocuencia, su fotogenia, su lenguaje no verbal y su duende se corroboran como factores decisivos en el duelo mediático.

En España, los dos cara a cara de 1993 organizados entre Felipe González y José María Aznar mostraron, igualmente, la importancia que adquiere la imagen en la pequeña pantalla. Esto se sustenta en que, de no haberse celebrado el segundo debate, González hubiera perdido, probablemente, las elecciones. En el primer duelo, González se mostró intranquilo ante su oponente y "pecó de arrogancia, petulancia y soberbia política (...), evitando insistentemente la mirada de su oponente (...) y desacreditando su presencia en el estudio" (Barnés, 2007, p.120) lo que generó rechazo entre los espectadores. En el segundo, el cambio de actitud del candidato socialista hacia una postura más dinámica y enérgica desorientó a Aznar y le permitió ganarse de nuevo la confianza de los votantes.

Los dos debates de 1993 fueron un precedente claro en nuestro país de la importancia que adquiere la imagen proyectada en televisión para los futuros aspirantes, pues brinda a los espectadores la posibilidad de "observar y juzgar a los candidatos en un espacio donde se manifiestan sus conocimientos habilidades, incapacidades y frustraciones" (Marín, 2003, p.208) y, desde entonces, se han convertido en el formato clave para conocer a los candidatos y sus propuestas.

La mediatización de la campaña electoral y el relieve que adquiere la celebración de los debates dentro de esta ha llevado a los distintos especialistas en comunicación política a negociar y organizar distintos aspectos relacionados con el lugar de celebración, el escenario, los contenidos, la realización, el profesional que lo moderará o la presencia del público en plató (Pérez y Melgosa, 2015; Rímoli, 2018). Sin embargo, es en la figura del candidato donde con más ahínco se centran todos los esfuerzos de los asesores.

En este espacio el líder está más indefenso y por este motivo, para que el mensaje llegue a todos los públicos, en los debates televisados es muy importante la armonía tanto de lo que se dice con palabras como de lo que se transmite a través del canal no verbal. (Rímoli, 2018, p.149)

Por eso, sin que se hayan de anteponer los gestos a las palabras, los códigos del lenguaje no verbal en la impresión que reciben los espectadores de los políticos son vitales, sobre todo cuando el candidato trata de transmitir distintas emociones a través de su mensaje. De ahí que, en muchas ocasiones, el canal no verbal se presente como el mejor si a través de la vía verbal es difícil comunicar los sentimientos (Caramelo, 
2020). Por lo tanto, el candidato que aspire a ganar unos comicios debe tener en cuenta las cinco categorías que influyen en el mensaje: la kinesia (los gestos, la postura y las maneras), el aspecto físico y la apariencia, la proxémica (las distancias), el paralenguaje (cualidades vocales) y el entorno.

Sin embargo, muchos comportamientos no verbales se encuentran asociados a una cuestión de género que legitiman la condición de hombre o mujer en el escenario político, de ahí que el estudio de estos códigos en los distintos agentes que conforman la política pueda arrojar luz sobre este tema. Además, las investigaciones únicamente sobre comunicación no verbal en líderes políticas son escasas, por lo que aumentar los estudios, previos a los de la comparación entre géneros, son esenciales para conformar una literatura sólida alrededor de esta materia, aún más cuando la presencia de mujeres en el escenario político ha ido en aumento en los gobiernos democráticos de todo el mundo (Hillary Clinton o Angela Merkel, son algunos de los ejemplos). Es por ello que este estudio, mediante la retransmisión del debate regional televisado por el canal 24 horas el 26 de noviembre de 2018, en el que se confrontaron las dos políticas candidatas Susana Díaz y Teresa Rodríguez, pretenda extraer cuáles son los comportamientos no verbales que aplican las candidatas en términos persuasivos, atendiendo a su kinesia.

\subsection{El comportamiento kinésico aplicado al candidato/a político/a}

En este apartado se detallan las principales funciones y significados de las posturas y los gestos que engloba la kinesia y que son claves en esta investigación. Estas categorías se asocian, además, con su traslación a una comunicación positiva o negativa en términos persuasivos y están basadas en los estudios realizados por Morris (1987), Pease (2006) y Hernández y Rodríguez (2009), entre otros.

La postura de pie de acercamiento, en la que el cuerpo se inclina hacia adelante, es una posición que denota atención e interés. La mirada firme y franca y la mirada feroz indican, en el primer caso, interés y atención; en el segundo, se exhibe agresividad y fortaleza de carácter. Al mismo tiempo también una capacidad dialogante y, en el último caso, asombro y autoritarismo. Este gesto se identifica cuando los "ojos permanecen muy abiertos mirando mientras el ceño está fruncido" (Hernández y Rodríguez, 2009, p.73).

Dentro de los gestos faciales, la sonrisa también tiene un peso importante en la expresividad del rostro en televisión "la sonrisa puede hacer cambiar la impresión que una persona tiene de nosotros o transformar cualquier situación. Además, tiene un gran poder de seducción sobre los demás" (Hernández y Zamora-Martínez, 2017, p.31). En este caso, la sonrisa auténtica, que provoca pliegues en los ojos, la más duradera e intensa, significa sinceridad. 
Los gestos corporales con los brazos que están asociados a una comunicación positiva son los brazos abiertos, un gesto de apertura a la comunicación, que invita al abrazo. En cuanto a los realizados con las manos están la palma de la mano hacia arriba, el puño cerrado oscilante y ambos puños cerrados, el gesto del campanario, del anillo, enseñar los pulgares y, los ilustradores bastones/batuta, apuntadores, espaciales y manos ventosa. El primero tiene un significado de transparencia, honestidad, capacidad de diálogo y tolerancia. Mientras, el segundo sirve para remarcar e imprimir fuerza a ciertas afirmaciones. El tercero, es un gesto relacionado con la hostilidad y la agresividad. El gesto del campanario indica confianza y seguridad y se identifica cuando "los dedos de una mano presionan ligeramente los de la otra formando un campanario" (Hernández y Rodríguez, 2009, p.79) y enseñar los pulgares se asocia al dominio y la agresividad.

Finalmente, los ilustradores se utilizan "para reforzar lo que se dice de manera oral. Por lo general se realizan con las manos, aunque también pueden realizarse con el rostro" (Hernández y Zamora-Martínez, 2017, p.33). Los bastones/batuta se emplean para enfatizar alguna parte del discurso. Los apuntadores pueden resultar amenazantes y "sirven para señalar la situación espacial o para identificar a una persona o cosa" (Hernández y Rodríguez, 2009, p.79). Los ilustradores espaciales ayudan a ilustrar el discurso verbal y, las manos ventosas transmiten tranquilidad y seguridad. Se identifican cuando las yemas de los dedos de ambas manos se unen.

\section{OBJETIVOS Y METODOLOGÍA}

El objetivo general de esta investigación, como se ha señalado en la introducción, es contribuir a incrementar los estudios sobre comunicación no verbal en el terreno político $y$, especialmente, aumentar las investigaciones que se centran en las candidatas en el contexto de los debates electores.

Para ello, se han fijado los siguientes objetivos específicos (OE):

OE1: Realizar una radiografía de los patrones no verbales de las candidatas Susana Díaz y Teresa Rodríguez para determinar su grado de persuasión en clave tanto positiva como negativa a la hora de trasladar sus mensajes durante el transcurso del debate.

OE2: Establecer una comparativa de ambas candidatas que permita discernir cuál de ellas muestra variables posturales y gestuales más persuasivas y por tanto más eficaces para enfatizar y potenciar su estilo oratorio.

OE3: Determinar si existe algún recurso no verbal más recurrente a la hora de potenciar su mensaje verbal y si este coincide en ambas líderes políticas.

Asimismo, se han formulado las siguientes hipótesis de investigación: 
HIG (Hipótesis general): La trayectoria y la experiencia política de la candidata del Partido Socialista de Andalucía, Susana Díaz, le otorga mayor seguridad y confianza en su estilo oratorio, lo que hace que proyecte un liderazgo político más positivo en términos persuasivos frente a su oponente, Teresa Rodríguez, que acude a un debate electoral televisado por primera vez.

HIE (Hipótesis específica): La gestualidad efectuada con las manos es el recurso corporal más utilizado por ambas candidatas para enfatizar las 'ideas fuerza de su discurso' y para dotar de expresividad sus disertaciones verbales.

\subsection{Estrategia metodológica}

La técnica de investigación utilizada en este trabajo es el análisis de contenido cuantitativo, puesto que es una de las metodologías más adecuadas para el estudio del comportamiento no verbal de los líderes políticos (Gauthier, 1998). Se trata de una técnica que se ajusta a la perfección a este objetivo debido a que lo que se pretende es sistematizar aquellas variables no verbales más representativas durante el transcurso del debate (Bardin, 1996; Krippendorff, 1990).

La elección de esta herramienta se debe a que permite aplicar de forma sistemática unas reglas fijadas previamente que miden la frecuencia con la que aparecen unos elementos de interés en el conjunto de un mensaje informativo seleccionado, para estudiar aquellos aspectos más significativos de acuerdo a los propósitos de la investigación. A esto se suma su configuración como un instrumento imprescindible para procesar grandes volúmenes de información audiovisual. Su utilización posibilita manejar cientos de unidades cuya descodificación aporta fiabilidad y validez (Berganza y Ruiz, 2013).

\subsection{Población y muestra}

La muestra de análisis de esta investigación fue el debate electoral celebrado el 26 de noviembre de 2018 en RTVE (se emitió a las 22:00 horas en directo en La 1 para Andalucía, en el Canal 24 horas y en Radio 5 Todo Noticias) con motivo de las elecciones a la presidencia de Andalucía en España. En él participaron los cuatro partidos con representación parlamentaria: Susana Díaz (PSOE), Juan Manuel Moreno (PP), Teresa Rodríguez (Adelante Andalucía) y Juan Marín (Ciudadanos). Sin embargo, para realizar el análisis comparativo del comportamiento no verbal exhibido, las investigadoras seleccionaron, únicamente, a las dos líderes femeninas presentes en el debate.

La unidad de clasificación fueron los cuatro bloques temáticos en los que se dividió el debate: Bloque 1 (política económica); Bloque 2 (servicios públicos y derechos); Bloque 3 (trasparencia) y Bloque 4 (política territorial). La duración de estos bloques fue en total 
de 20 minutos, disponiendo cada candidato de 5 por bloque. Cada líder tuvo opción de distribuirse ese tiempo con libertad.

Para facilitar la codificación, se analizaron de forma independiente todas las intervenciones tanto de Díaz como de Rodríguez. Por tanto, la unidad de enumeración, es decir, la base sobre la que se tabuló el contenido fueron los segundos que cada candidata apareció en pantalla (Igartua, 2006). Para obtener el cómputo global de variables no verbales a esas intervenciones se sumó el minuto inicial y el minuto de oro con el que se cerró este debate.

\subsection{Instrumentos de recogida de información}

Esta investigación se vertebra en un profundo análisis de los aspectos más significativos del comportamiento kinésico tanto en su dimensión facial como corporal. En la primera, el estudio aborda patrones posturales y gestos manuales mientras que, en la segunda, se han codificado las variables relativas a la mirada y la sonrisa.

Los datos han sido registrados en una ficha de análisis que, aplicada a este tipo de debates, permite reconocer el tipo de discurso que se aborda, puesto que ofrece la opción de discernir y captar en su interior los elementos verdaderamente útiles para responder a los objetivos e hipótesis. Esta herramienta ha sido validada en varias investigaciones anteriores desarrolladas en el ámbito de la comunicación política y sistematizada en el artículo científico titulado "Investigar en comunicación no verbal: un modelo para el análisis del comportamiento kinésico de líderes políticos y para la determinación de su significación estratégica" (Hernández y Rodríguez, 2009). Se trata de un procedimiento que permite recoger los patrones no verbales asociados a ciertas conductas y actitudes propias de los líderes políticos. Se centra, por tanto, en el emisor que lanza el mensaje político. No obstante, de cara al futuro, en este punto sería interesante articular estudios (a modo de cuestionarios o entrevistas) que incluyeran las percepciones que la opinión pública recibe en relación al lenguaje corporal de los sujetos analizados, con el objetivo de poder poner en común ambos resultados y obtener conclusiones más completas (Véase el estudio de Luengo citado en esta investigación).

Así, la ficha de análisis agrupó 42 subvariables asociadas a las variables: la postura (4), los gestos faciales realizados con la mirada (11), los gestos faciales efectuados con la sonrisa (11) y los gestos corporales ejecutados con las manos (16).

\section{Tabla 1}

Ficha de análisis de contenido

\begin{tabular}{|l|c|c|}
\hline \multicolumn{1}{|c|}{ POSTURA (DE PIE) } & Significado conceptual & Connotación \\
\hline Acercamiento & Inclinación hacia adelante & Positivo \\
\hline
\end{tabular}


La comunicación no verbal en las elecciones andaluzas 2018. Susana Díaz versus Teresa Rodríguez en el

\begin{tabular}{|c|c|c|}
\hline Retirada & Inclinación hacia atrás & Negativo \\
\hline Expansión & Expansión del cuerpo & Negativo \\
\hline Contracción & Contracción del cuerpo & Negativo \\
\hline $\begin{array}{l}\text { GESTOS FACIALES } \\
\text { (MIRADA) }\end{array}$ & Significado conceptual & $\begin{array}{c}\text { Connotación } \\
\text { persuasiva }\end{array}$ \\
\hline Bajar los ojos & --- & Negativo \\
\hline Mirada hacia arriba & --- & Negativo o Neutro \\
\hline Mirada de arriba abajo & --- & Negativo \\
\hline Mirada lateral o de soslayo & --- & Negativo \\
\hline Mirada firme y franca & $\begin{array}{c}\text { Mirada sostenida } \\
\text { hacia algo o alguien }\end{array}$ & Positivo \\
\hline Mirada feroz & Ojos abiertos y ceño fruncido & Negativo \\
\hline Mirada huidiza & Se retira la vista & Negativo \\
\hline Mirada de sorpresa & $\begin{array}{l}\text { Se abren los ojos y } \\
\text { se ve la zona blanca } \\
\text { por encima del iris }\end{array}$ & Positivo o Neutro \\
\hline Entrecerrar los ojos & --- & Negativo o Neutro \\
\hline Ojos brillantes & $\begin{array}{c}\text { Ojos sobrecargados } \\
\text { de lágrimas }\end{array}$ & $\begin{array}{l}\text { Orgullo o triunfo: } \\
\text { Positivo } \\
\text { Ira o rabia: Negativo }\end{array}$ \\
\hline Ojos desenfocados & Mirada hacia el infinito & Negativo o Neutro \\
\hline $\begin{array}{c}\text { GESTOS FACIALES } \\
\text { (SONRISA) }\end{array}$ & Significado conceptual & $\begin{array}{l}\text { Connotación } \\
\text { persuasiva }\end{array}$ \\
\hline Sonrisa auténtica & $\begin{array}{l}\text { Provoca pliegues } \\
\text { en los ojos }\end{array}$ & Positivo \\
\hline Sonrisa de temor & Es horizontal & Negativo o Neutro \\
\hline Sonrisa de desdén & Provoca pliegues en las comisuras & Negativo \\
\hline Sonrisa triste & Es asimétrica & Negativo o Neutro \\
\hline Sonrisa sádica o cruel & Los labios se afinan & Negativo \\
\hline
\end{tabular}

Ámbitos. Revista Internacional de Comunicación | ISSN: 1139-1979 | E-ISSN: 1988-5733, №. 49. (2020) 


\begin{tabular}{|c|c|c|}
\hline & y se eleva el superior & \\
\hline Sonrisa burlesca & Los labios se eleven de forma insolente & Negativo \\
\hline Sonrisa amortiguada & Los labios se aprietan & Negativo \\
\hline Sonrisa falsa & Asimétrica y sin pliegues & Negativo \\
\hline Sonrisa de labios tensos & Los labios forman una línea recta & Negativo \\
\hline Sonrisa torcida & $\begin{array}{l}\text { Los labios se tuercen hacia un lado del } \\
\text { rostro }\end{array}$ & Negativo \\
\hline $\begin{array}{l}\text { Sonrisa de mandíbula hacia } \\
\text { abajo }\end{array}$ & La mandíbula inferior empuja hacia abajo & Positivo \\
\hline $\begin{array}{c}\text { GESTOS CORPORALES } \\
\text { (LAS MANOS) }\end{array}$ & Significado conceptual & $\begin{array}{c}\text { Connotación } \\
\text { persuasiva }\end{array}$ \\
\hline $\begin{array}{l}\text { Palma de la mano } \\
\text { hacia arriba }\end{array}$ & --- & Positivo \\
\hline $\begin{array}{l}\text { Palma de la mano } \\
\text { hacia abajo }\end{array}$ & --- & Negativo \\
\hline Puño cerrado oscilante & --- & Negativo \\
\hline Ambos puños cerrados & --- & Negativo \\
\hline Manos unidas & --- & Negativo \\
\hline El campanario & $\begin{array}{c}\text { Los dedos de una mano presionan los de } \\
\text { la otra formando un campanario }\end{array}$ & Positivo \\
\hline Gesto del anillo & $\begin{array}{c}\text { El pulgar y el índice } \\
\text { forman un círculo } \\
\text { mientras el resto de } \\
\text { dedos apuntan hacia arriba }\end{array}$ & Positivo \\
\hline $\begin{array}{l}\text { Mano que sujeta } \\
\text { la muñeca }\end{array}$ & --- & Negativo \\
\hline Mano que sujeta el brazo & --- & Negativo \\
\hline Enseñar los pulgares & --- & Negativo \\
\hline |llustradores bastones & $\begin{array}{l}\text { Marcan el ritmo del } \\
\text { mensaje }\end{array}$ & Positivo \\
\hline
\end{tabular}




\begin{tabular}{|l|c|c|}
\hline Ilustradores apuntadores & $\begin{array}{r}\text { Movimientos deícticos dirigiéndose a } \\
\text { alguien }\end{array}$ & Negativo \\
\hline Ilustradores espaciales & Describen espacios, formas y tamaños & Positivo \\
\hline $\begin{array}{l}\text { Ilustradores manos } \\
\text { ventosa }\end{array}$ & $\begin{array}{r}\text { Se unen las yemas de ambas manos } \\
\text { Autoadaptadores }\end{array}$ & $\begin{array}{r}\text { Rascarse, tocarse, } \\
\text { morderse labios o uñas... }\end{array}$ \\
\hline Adaptadores de objetos & $\begin{array}{r}\text { Tocar o jugar } \\
\text { con objetos }\end{array}$ & Negativo \\
\hline
\end{tabular}

Fuente: Elaboración propia

\section{RESULTADOS}

Los hallazgos obtenidos se presentan en este apartado de forma estructurada atendiendo a las variables formuladas: los gestos posturales, faciales y corporales.

\subsection{La postura: de pie}

Tal y como puede apreciarse en el gráfico, el patrón postural que se obtiene arroja dos tendencias prácticamente simétricas. Tanto Susana Díaz como Teresa Rodríguez se mantienen casi todo el tiempo que aparecen en pantalla mostrando una postura de acercamiento. Una variable que se relaciona con la apertura a la comunicación y la cercanía. En términos porcentuales es Susana Díaz quien la exhibe la mayor parte del tiempo $(77,5 \%)$ frente al $61,29 \%$ de su contrincante. Asimismo, ambas aparecen mostrando una postura negativa, denominada postura de contracción y que se manifiesta con hombros hundidos y cabeza baja. Es una postura de sometimiento que Díaz exhibe en un 22,6\% del tiempo mientras que Teresa Rodríguez lo hace en un $27,42 \%$. Aunque en algunas ocasiones ambas líderes se contraen para mirar el guion, la actitud que transmiten no es acertada. 


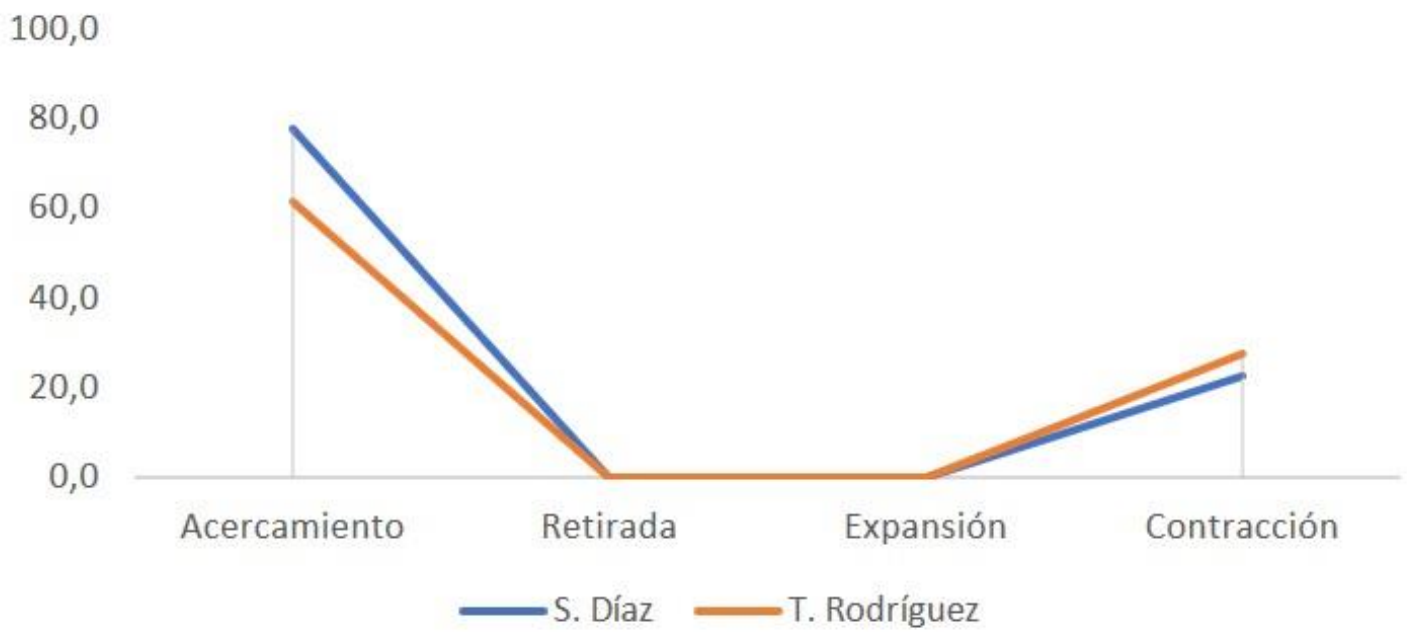

Figura 1. Tipos de postura

Fuente: Elaboración propia

\subsection{Los gestos faciales: la mirada}

En la siguiente variable no verbal, la mirada, vuelve a llamar la atención la obtención de dos líneas gráficas prácticamente gemelas. Las dos dirigentes son parcas a la hora de mostrar variedad de miradas. Así, de los once tipos de miradas tipificadas, solo se proyectan tres, en el caso de Díaz y dos, en el de Rodríguez. La que más se pudo observar en ambos casos fue la firme y franca (72,6\% Díaz y 58,1\% Rodríguez). Es una mirada asociada a la transparencia y a la atención inteligente; por tanto, sería muy positiva en términos persuasivos. Las dos líderes también aparecieron con la mirada hacia bajo de forma sostenida, sobre todo para leer algunas partes del texto que disponían a modo de apoyo. Susana Díaz lo hizo un $27,4 \%$ del tiempo y Teresa Rodríguez un $29 \%$. Este tipo de mirada, aunque transmite humildad y modestia, en el terreno político va unida al sometimiento y la falta de carácter. Finalmente añadir que los datos también apuntan a que Díaz mostró una mirada feroz el 8,1\% del tiempo, un parámetro que denota fortaleza de carácter y determinación. 


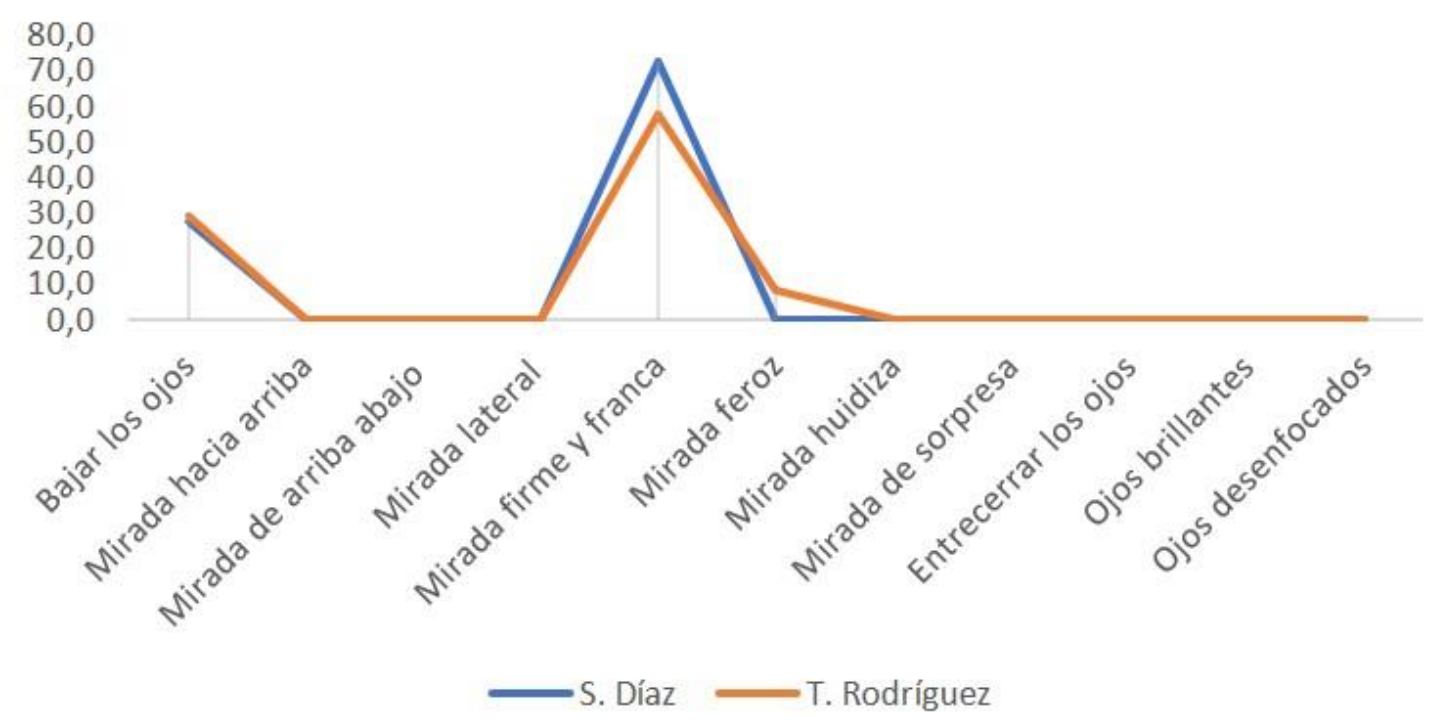

Figura 2. Tipos de miradas

Fuente: Elaboración propia

\subsection{Los gestos corporales: las manos}

La gráfica de los movimientos que se realizan con las manos es la que mayor profusión de resultados arroja. En este caso, el comportamiento de Díaz y Rodríguez ofrece pistas muy valiosas para determinar su grado de persuasión. Claramente es Susana Díaz la candidata que mayor riqueza gestual establece con sus movimientos de manos mostrando además un equilibrio en los mismos. En detalle se observa que los movimientos más utilizados son los ilustradores bastones $(17,6 \%)$ que marcan el ritmo de la alocución, seguidos de la palma de la mano hacia arriba $(16,7 \%)$ que indica honestidad. Asimismo, son destacables también los ilustradores espaciales que señalan formas y lugares (16,30\%) y las manos ventosa (reflexión) $(14,10 \%)$. En menor medida el repertorio de Díaz también cuenta con ilustradores apuntadores $(8,3 \%)$ que incriminan al contrario y el gesto del anillo (7\%) que se asocia a la reflexión. De la misma forma aparece mostrando adaptadores de objetos (sujeta papeles a modo de evidencia y se ayuda de un bolígrafo para controlar tensión) y deja ver los pulgares mientras argumenta en una señal de superioridad. Al respecto, Teresa Rodríguez no cuenta con un abanico tan grande de gestos al mover sus manos, pero tampoco es desdeñable. Los más predominantes son los ilustradores bastones que utiliza en un $37,5 \%$ del tiempo para marcar el ritmo de su exposición, los espaciales para señalar formas a la hora de manifestar sus ideas $(29,17 \%$ del tiempo) y los ilustradores apuntadores, que afloran un $15,4 \%$ del tiempo con intención de increpar al resto de candidatos. Rodríguez muestra en menor medida adaptadores de objetos -agarra un bolígrafo para rebajar tensión$(6,5 \%)$ y la palma de la mano hacia abajo $(2,9 \%)$ denotando agresividad. 


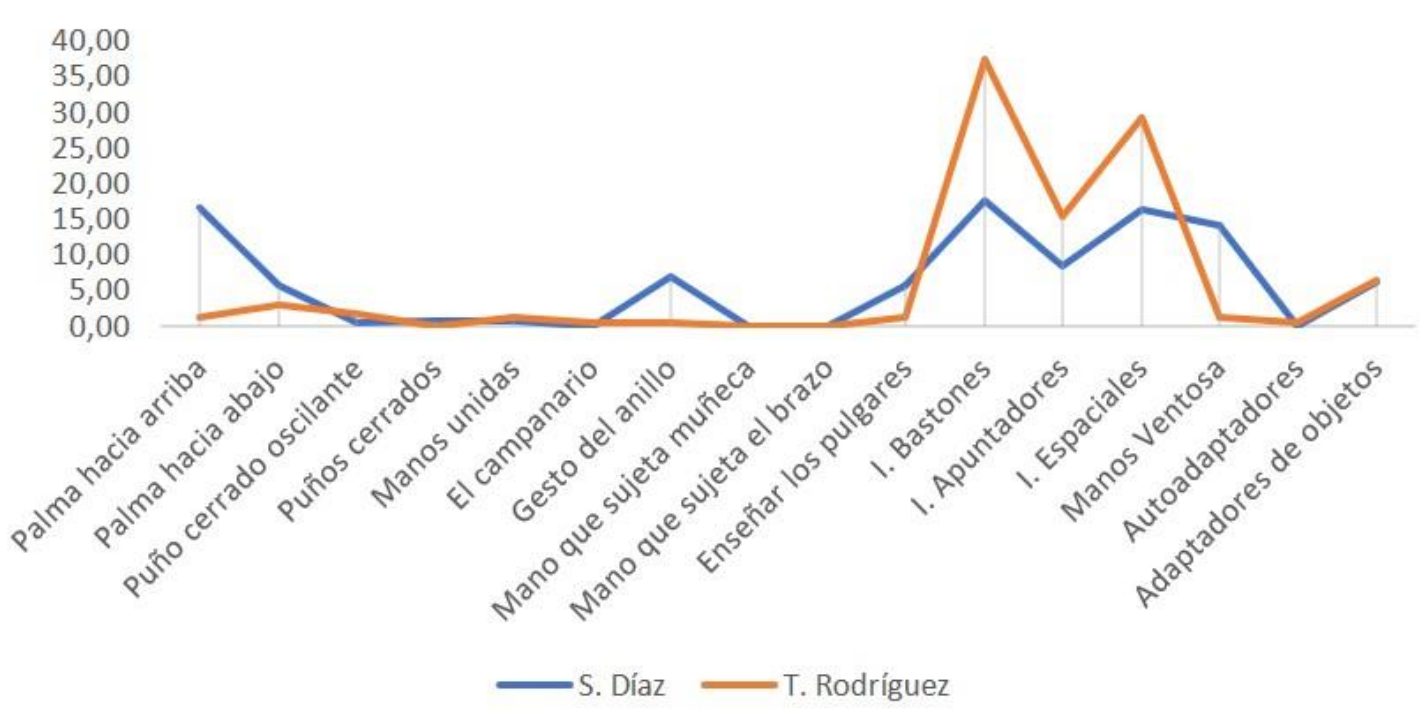

Figura 4. Movimientos con las manos Fuente: Elaboración propia

\section{DISCUSIÓN Y CONCLUSIONES}

En términos posturales ambas políticas aciertan en su comunicación no verbal. Predomina la postura de acercamiento que simboliza apertura y cercanía con el espectador al que intentan vincular con su discurso. En ambos casos representa una fortaleza persuasiva.

La mirada es uno de los factores comunicativos a tener más en cuenta en el análisis del lenguaje no verbal. Sin embargo, en este debate no hubo variedad, un aspecto que resta riqueza a la hora de persuadir. Las tendencias gráficas vuelven a ser simétricas y en ellas predomina la mirada firme y franca (ver gráfico 2) que se asocia a la atención y al interés. Es importante tener en cuenta que casi una tercera parte del tiempo las candidatas aparecieron cabizbajas con la mirada hacia al atril, una señal de sumisión y búsqueda de seguridad que puede interpretarse como una debilidad persuasiva.

Fue Susana Díaz, quien desplegó un comportamiento no verbal más adecuado. De hecho, el recuento apunta a un total de 282 variables gestuales asociadas a una comunicación eficaz en el ámbito postural, facial y corporal, frente a las 207 que exhibió su oponente, la representante de Adelante Andalucía, Teresa Rodríguez. Estos datos corroboran la hipótesis general de esta investigación que sostenía que "la trayectoria y la experiencia política de la candidata del Partido Socialista de Andalucía, Susana Díaz, le otorga mayor seguridad y confianza en su estilo oratorio, lo que hace que proyecte un liderazgo político más positivo en términos persuasivos frente a su oponente, Teresa Rodríguez, que acude a un debate electoral televisado por primera vez". 
Por otro lado, los movimientos que describen las manos son fundamentales para expresar el argumentario en televisión. Con las manos se ilustra, se manifiesta honestidad, se denota claridad y se ameniza. En el caso analizado es la candidata del PSOE quien sale vencedora frente a Teresa Rodríguez (ver gráfico 4). Destaca de Díaz tanto la variedad de movimientos como el acierto al utilizarlos en clave de positividad. Las palmas de las manos indicando no tener nada que ocultar, los ilustradores que facilitan la asimilación de la alocución y las manos ventosa que invitan a la reflexión son, sin duda, sus fortalezas. En el lado opuesto, encontramos a una Teresa Rodríguez más repetitiva y con un repertorio menor. Abusa de los ilustradores bastones y apenas exhibe gestos en clave positiva. Es uno de los aspectos que debería mejorar. En cualquier caso, los datos también corroboran la hipótesis específica que afirmaba que "la gestualidad efectuada con las manos es el recurso corporal más utilizado por ambas candidatas para enfatizar las 'ideas fuerza de su discurso' y para dotar de expresividad sus disertaciones verbales".

Finalmente, cabe destacar que, aunque fueron las manos el recurso no verbal más empleado tanto por Díaz como por Rodríguez para ilustrar sus palabras, lo cierto es que la sonrisa también ocupó un lugar relevante en su repertorio gestual. De hecho, es importante subrayar que, aunque la simpatía es una de las cualidades más valoradas en los líderes actuales y transmite amabilidad generando empatía, las protagonistas de este debate sonrieron bastante a menudo, pero de forma desacertada. Las sonrisas de Díaz se asocian a la impostura, la incomodidad y la ironía hacia los argumentos esbozados por sus contrincantes. Esta actitud le hace parecer demasiado seria y poco simpática, otorgándola una imagen emocionalmente dura. Mientras, Teresa Rodríguez, aunque sonríe menos y en un $66,7 \%$ del tiempo de forma tensa, lo contrarresta apareciendo en un $33,3 \%$ de las ocasiones haciéndolo de forma auténtica, lo que le hace parecer natural y cercana.

Esta investigación pretende servir de base para ahondar en el estudio del comportamiento no verbal de las líderes políticas actuales, un campo de estudio menos explorado que en su dimensión masculina. Asimismo, abre las puertas a una comparativa con sus homólogos para determinar la posible existencia de estrategias no verbales diferentes al observar los patrones gestuales en televisión. También, cabe apuntar que sería de sumo interés poder recoger las percepciones que la opinión pública tiene acerca del comportamiento no verbal de los líderes analizados para establecer una comparativa entre los patrones verbales desplegados por el emisor y las sensaciones que le llegan al receptor. Para esta tarea podrían diseñarse técnicas e instrumentos de recogida de información tales como cuestionarios o entrevistas que permitieran su posterior tratamiento estadístico. 


\section{Notas}

1 Se celebraron dos debates electorales con los principales candidatos a la presidencia del Gobierno: Pablo Casado, Pablo Iglesias, Albert Rivera y Pedro Sánchez. El primero, organizado por Radiotelevisión Española, se produjo el 22 de abril de 2019 y el segundo, administrado por Atresmedia, tuvo lugar el 23 de abril de 2019.

2 El debate fue retransmitido, simultáneamente, por las cadenas nacionales: La 1, Antena 3 y La Sexta.

${ }_{3}$ El primero de ellos, el 26 de septiembre de 1960 transmitido por la CBS de Chicago; el segundo el 7 de octubre del mismo año difundido por la cadena NBC; el tercero el 13 de octubre por la ABC; y el cuarto el 21de octubre, nuevamente, por la ABC. (Barnés, 2007, p.97).

\section{Referencias}

Bardin, L. (1996). Análisis de contenido. Madrid, España: Akal.

Barlovento Comunicación (2019). Audiencias lunes 4 de noviembre de 2019. Recuperado de: https://bit.ly/2XfSRks

Barnés, J. S. (2007). El candidato ante los medios: telegenia e imagen política. Madrid, España: Fragua.

Berganza, R. M. ํ y Ruiz, J.J. (2013). Investigar en comunicación. Guía práctica de métodos y técnicas de investigación social en comunicación. Madrid, España: McGraw Hill.

Berrocal, S. (2011). Los debates electorales en televisión. Un estudio del caso español en las elecciones de 2008. En G. López García (Ed.), Política binaria y spam electoral. Elecciones Generales 2008: nuevas herramientas, viejas actitudes (pp. 144-168). Valencia, España: Tirant Lo Blanch.

Caramelo, L. M. (2020). Análisis del discurso emocional de Donald Trump en la campaña electoral de 2016. Ámbitos. Revisa Internacional de Comunicación 47, pp. 267-287. doi: 10.12795/Ámbitos.2020.i47.13

Espizua, I. \& Padilla, G. (2017). La imagen y el estilo de la mujer política española como elementos básicos de su comunicación. Revista de comunicación de la SEECI. 42, pp. 62-84. doi: https://doi.org/10.15198/seeci.2017.42.62-84

García-Marín, J.; Calatrava, A. \& Luengo, Ó. G. (2018). Debates electorales y conflicto. Un análisis con máquinas de soporte vital (SVM) de la cobertura mediática de los debates en España desde 2008). El profesional de la información. 27(3), pp. 624-632. Recuperado de https://doi.org/10.3145/epi.2018.may.15

García-Marín, J. (2015). La cobertura mediática de los debates electorales en España. Revista Española de Ciencia Política. 38, pp. 135-161. Recuperado de https://bit.ly/3bX5J2Y 
Gauthier, G. (1998). El análisis de contenido de los debates políticos televisados. En J. Mouchon; A. Gosselin \& G. Gauthier, Comunicación y política (pp. 394-411). Barcelona, España: Gedisa.

González, A. (2009). Micropolítica. Ideas para cambiar la comunicación política. Barcelona, España: Autoedición.

Gubern, R. (25 de febrero de 2008). Duelo de imágenes entre los dos candidatos. El Mundo. Recuperado de https://bit.ly/38Mec8e

Hernández, M. \& Rodríguez, I. (2009). Investigar en comunicación no verbal: un Modelo para el análisis del comportamiento kinésico de líderes políticos y para la determinación de su significación estratégica. Enseñanza \&Teaching. 27(1), pp. 61-94. Recuperado de https://bit.ly/34urpPQ

Hernández, M. (2012). Análisis comparativo del comportamiento kinésico del presidente del Gobierno, José Luis Rodríguez Zapatero, en función de la temática discursiva (curso político 2006-2007). Doxa comunicación. 15, pp. 81-106. Recuperado de https://bit.ly/2RV3BBY

Hernández, M. \& Zamora-Martínez, P. (2017). Análisis comparativo del comportamiento kinésico de las presentadoras de magazine en la televisión generalista. Comunicación. Revista Internacional de Comunicación Audiovisual, Publicidad y Literatura. 15, pp. 26-46. Recuperado de https://bit.ly/2EmEfVJ

Igartua, J.J. (2006). Métodos cuantitativos de investigación en comunicación. Barcelona, España: Bosch.

Krippendorff, K. (1990). Metodología de Análisis de Contenido. Teoría y Práctica. Madrid, España: Paidós Comunicación.

Lasheras, Z. (2014). La comunicación no verbal en los debates electorales. El caso de España en 2011 (Tesis de pregrado). Universidad de Valladolid, Valladolid, España.

López, A. \& Méndez, E. (2009). La interrupción como mecanismo regulativo de las interacciones verbales. Los debates electorales Zapatero-Rajoy 2008. Español Actual. 92, pp. 159220. Recuperado de https://bit.ly/2syvWDs

Luengo, Ó. G. (2011). Debates electorales en televisión: Una aproximación preliminar a sus efectos inmediatos. Revista Española de Ciencia Política. 25, pp. 81-96. Recuperado de https://bit.ly/2JOeeS8

Marín, B. (2003). Debates electorales por televisión. En S. Berrocal Gonzalo (Coord.), Comunicación política en televisión y nuevos medios (pp. 207-243). Barcelona, España: Ariel.

Martín, L. (2002). Marketing político. Barcelona, España: Paidós. 
Morris, D. (1987). El cuerpo al desnudo: una sorprendente visión del cuerpo humano. Madrid, España: Folio.

Orzáiz, O. (2009). Comunicación no verbal y paraverbal en el debate político entre Zapatero y Rajoy. Tonos Digital. 18, pp. 1-17. Recuperado de https://bit.ly/36CPLbJ

Pease, A. y Pease, B. (2006). El lenguaje del cuerpo. Barcelona, España: Amat.

Pérez, C. \& Lancharro, M. I. (2017). Las estrategias de comunicación de Podemos y Ciudadanos en los debates electorales. Una aproximación mediante análisis de contenido: el debate de Atresmedia TV como estudio de caso. Razón y Palabra. 21(4_99), pp. 589-615. Recuperado de https://bit.ly/35uOZxo

Pérez, M. \& Melgosa, F. (2015). Los debates electorales realizados en España en 2008. Cuando la política se convierte en espectáculo televisado. Contratexto. 24, pp. 113-132. Recuperado de https://bit.ly/2V9Bu2b

Rímoli, R. (2018). Compendio experimental sobre comunicación política electoral y sus vínculos con la psicología. Miami, Estados Unidos: SV Graphiccon.

Rodríguez, I. \& Hernández, M. (2009). Claves de la espectacularización de la información política en televisión a través de los debates electorales de 2008: activación de la teoría del efecto destello'. En J. Marzal Felici; A. Casero Ripollés; F. J. Gómez Tarín (Eds.). Tendencias del periodismo actual en la era del espectáculo. (pp. 268-284) Madrid, España: Ediciones de las Ciencias Sociales

Rodríguez, I. \& Hernández, M. (2011). Análisis de la comunicación no verbal de José Luis Rodríguez Zapatero. Revista Latina de Comunicación Social. 65, pp. 436-449. Recuperado de https://bit.ly/34pFA8P

Torregrosa, J. (1999). Correlación de los patrones entonativos y kinésicos: análisis de un debate televisado. Conferencia llevada a cabo en I/ Congreso de Fonética Experimental, Sevilla, España. 